from a second ovum. Chaliex ${ }^{3}$ reports a case which appears to be very similar to the one reported above. In his case there were three male children; the first had a separate placenta, the other two had a common placenta with relamentous attachment of the cords. Westervelt ${ }^{4}$ notes a case of uni-ovular triplets which were all females.

With reference to the influence of heredity on the tendency to produce plural births it should be mentioned that twins had occurred twice in the girl's family within recent years ; two aunts, who were sisters, had each given birth to twins. Details regarding previous generations could not be obtained. Mirabeau, ${ }^{5}$ in an analysis of 75 cases of triplets, states that they occur usually in multiparæ who have had previous abortions and who belong to families where multiple births have been observed. He also found that the mothers of triplets were generally between the ages of 30 and 34 years. Wakley ${ }^{6}$ has clearly shown the influence of heredity on the tendency to produce plural births. The presence of triplets was not suspected until after the birth of the second child, the fotal heart sounds being very indistinct.

The Infirmary, Kensington, w.

\section{ON THE EFFECT OF TUBERCULIN ON THE GENERAL TUBERCULO-OPSONIC INDEX IN TUBERCULOUS PATIENTS.}

BY HENRY H. CLARKE, M.A., M.B., B.C. CANTAB., HONORARY PHXSICIAN TO THE LIVFRPOOL HOSPITAI FOR CONSUMPTION AND DISEASES OF THE CHEST AND PHYSICIAN IN CHARGE OF THE PATHOLOGICAL DEPARTMF NT; LATE BOLT FELLOW IN PATHOLOGY, UNIVERSITY OF LIVERPOOL; AND

HALLIDAY G. SUTHERLAND, M.B., CH.B. EdiN., Late Pathologist to the mospital.

IT has been frequently stated that the injection of a therapeutic dose of tuberculin is invariably followed by a fall in the opsonic index lasting from three days to three weeks. This period of low opsonic index is generally known as the "negative phase" and its duration varies with the amount injected. This negative phase is followed by a period of high opsonic index, which is known as the "positive phase" and lasts for a few days, after which the index returns to about its original level. It is generally believed that by reducing the dose to the minimum that will produce any effect the negative phase may be reduced and the positive phase correspondingly increased. The doses which have been most frequently used to produce these results range from $\frac{1}{10 \bar{\sigma}}$ to $\overline{1} \frac{1}{0}$ milligramme or even more.

CHART 1.

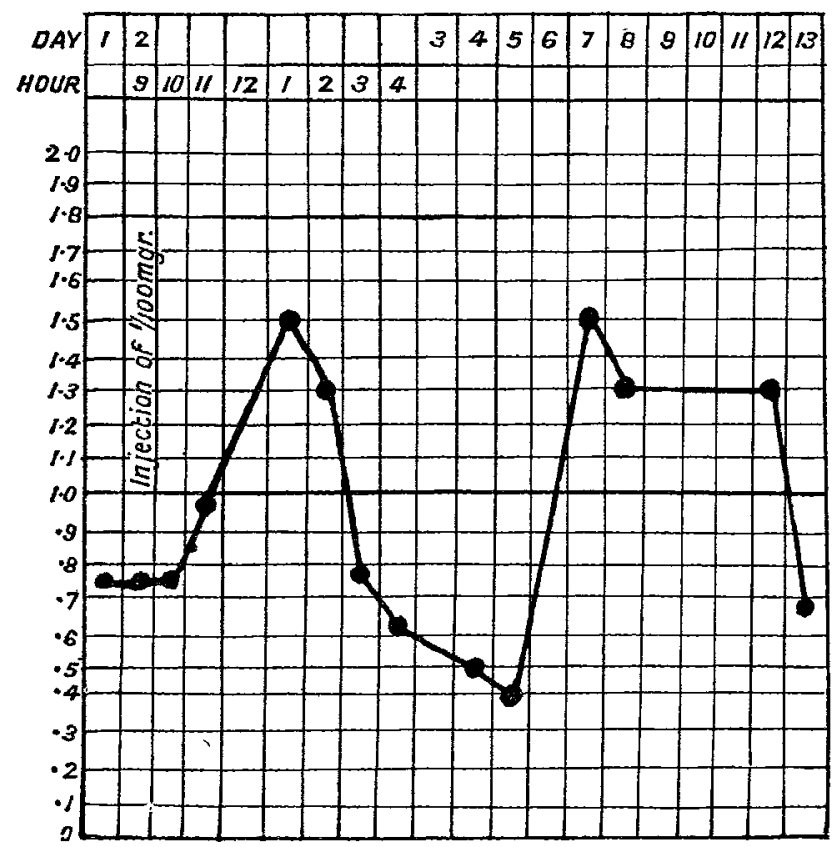

Showing effect of ${ }_{x} \frac{1}{0} t^{1} \mathrm{~h}$ milligramme of tuberculin (T.R.).

3 Journal de Médecine de Bordeaux, Oct. 6th, 1889.

4 Atlanta Medical Journal, August, 1889.
5 Correspondenzblatt für Schweizer Aertze, Basel. Dec. 15th, 1894. 6 THe La N CET, Nov. 23rd, 1895, p. 1289.
With a view to gaining more precise knowledge of the effect of a therapeutic injection we injected a phthisi al patic nt wi h il milligramme of Ko h's new tukerculin (T.R.) and estimated the opsonic index hourly for several hours with the following result. (See Chart 1.)

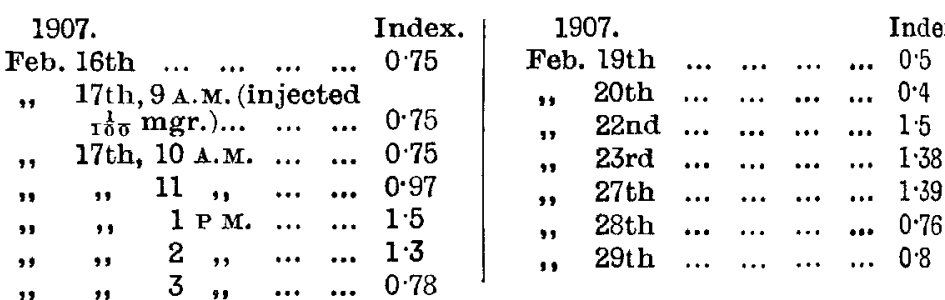

It will be observed that a rapid rise of the opsonic index cccurred within two hours of the injection; it rose to a maximum in four hours, fell to its original level in six hours, and was succeeded by the usual negative and positive phases. This initial rise may be called the pre-negative phase and has hitherto been overlooked owing to the fact that indices are rarely taken more than once a day. This pre-negative phase has since been independently observed and recorded by Dr. Clive Rivière. ${ }^{1}$

In order to explain these facts it is necessary to assume that when tuber zulin is injected into the body the opsonins present in the blood are absorbed by the bacillary débris. Fresh opsonins are then produced and as rapidly absorbed and it is thus that the negative phase is produced. But in accordance with the law of regeneration more opsonins are produced than suffice to replace those absorbed and sooner or later a point is reached at which the tuberculin is saturated. More and more opsonins are produced until the index begins to rise and the positive phase occurs. This theory will explain the negative and positive phases but not the initial rise. To explain this phase we must assume that at the moment of injection a minute fraction of the dose found its way immediately into the circulation, probably owing to rupture of some capillaries. This minute dose absorbed sufficient opsonin to set in motion the mechanism of immunity but not enough to cause more than an ex. ceedingly minute and transitory fall in the index. The index accordingly rose rapidly. The great bulk, however, of the injection remained at the site of inoculation until by dilatation of the capillaries and transudation of $1 \mathrm{ymph}$ it too was swept into the general circulation. This occurring some hours later the excess of opsonins produced were again absorbed and the negative phase set in.

CHART 2.

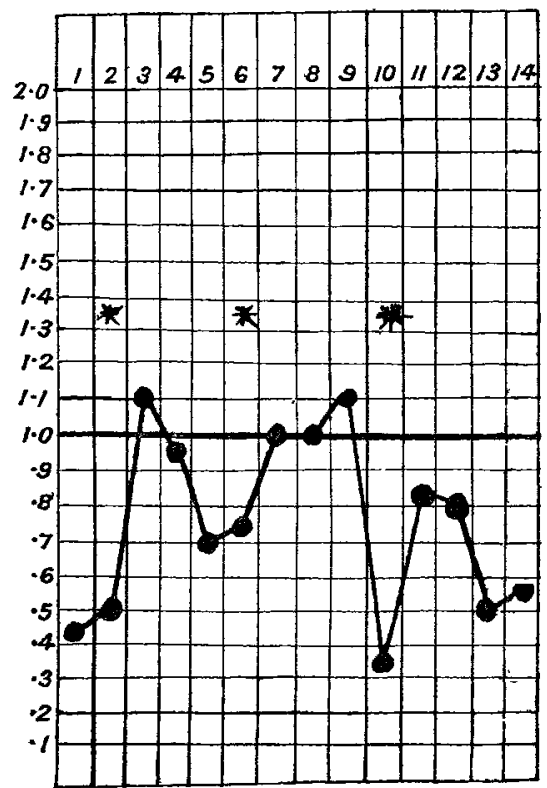

Showing effect of ror th milligramme of tuberculin (T.R.) the asterisk marking the date of dose.

If this explanation be correct, then it follows that if a sufficiently small dose be given the negative phase will be absent or so slight and transitory as to be negligible and the injection will be followed by an immediate rise. We have tested the truth of this explanation in five patients on 14 different occasions by injecting a dose of one-millionth of a cubic centimetre of tuberculin in a bulk of 
1.7 minims. (See Chart 2.) On every cccasion the injection was followed by an immediate positive phase lasting from two to four days, after which the index resumed nearly its former level and the negative phase was absent. In one case, that of a child aged ten years, the positive phase continued to the sixth day.

The next question which arose was whether by repeated injections one positive phase could be superimposed upon another, and if so how far could the process be carried.

Chart 3.

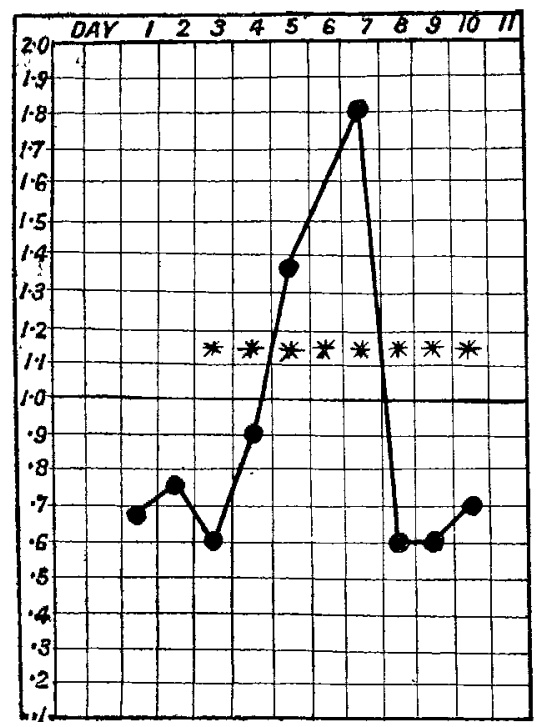

Showing effect of eight successive daily injections on dates indien by asterists of 10000 th milligramme of tuberculin (T.R.)

CHART 4.

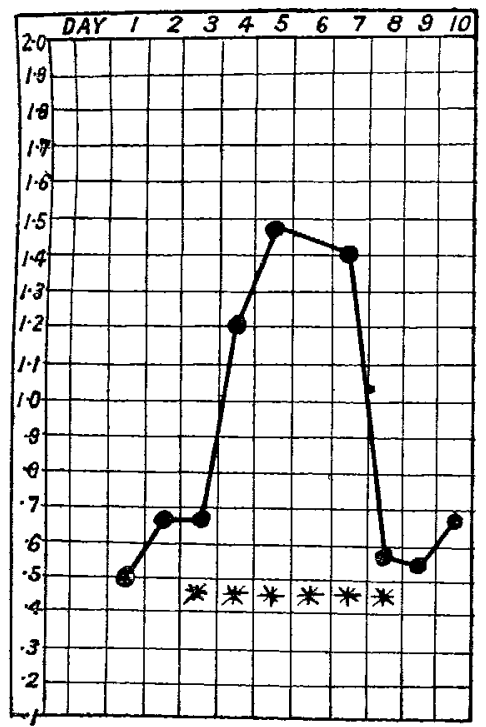

Showing effect of six successive daily injections on dates indicated by asterisks of 1 ? culin (T.R.)

With this object a dose of one-millionth of a cubic centimetre of tuberculin was injected into two patients on six successive days with the following results. (See Charts 3 and 4.)

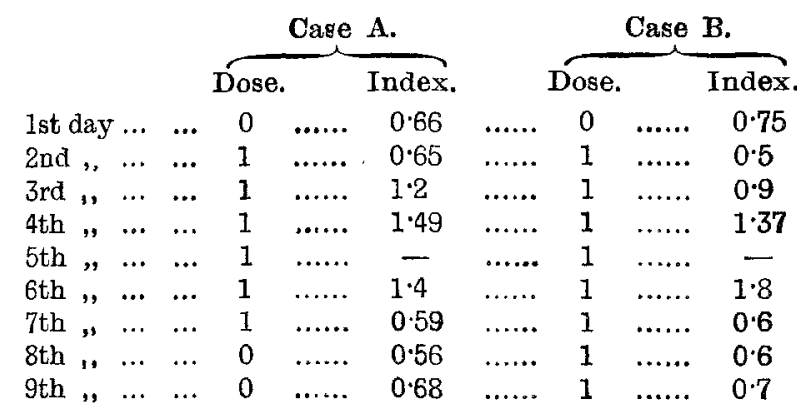

It will be seen that the first three doses were followed by successive rises in Case $A$ and the first four in Case B. In both cases the fifth injection was followed by a rapid fall to below the original level. Here the rise was higher and more prolonged than any previously produced in the same patients by a single injection and it seems reasonable to assume that this was due to a superimposition of positive phases. It is, however, obvious that this piling up of positive phases is only possible within very narrow limits. The mechanism of immunisation is one of delicate adjustment and is easily deranged. Apparently a very slight excess of tuberculin suffices to turn the scale and convert an over-production of opsonins into a deficit.

We have repeatedly tried the effect of injecting tuberculin according to the method suggested by Weber's law. This method has for its foundation the fact that in some classes of phenomena in order to produce effects

Citart 5.

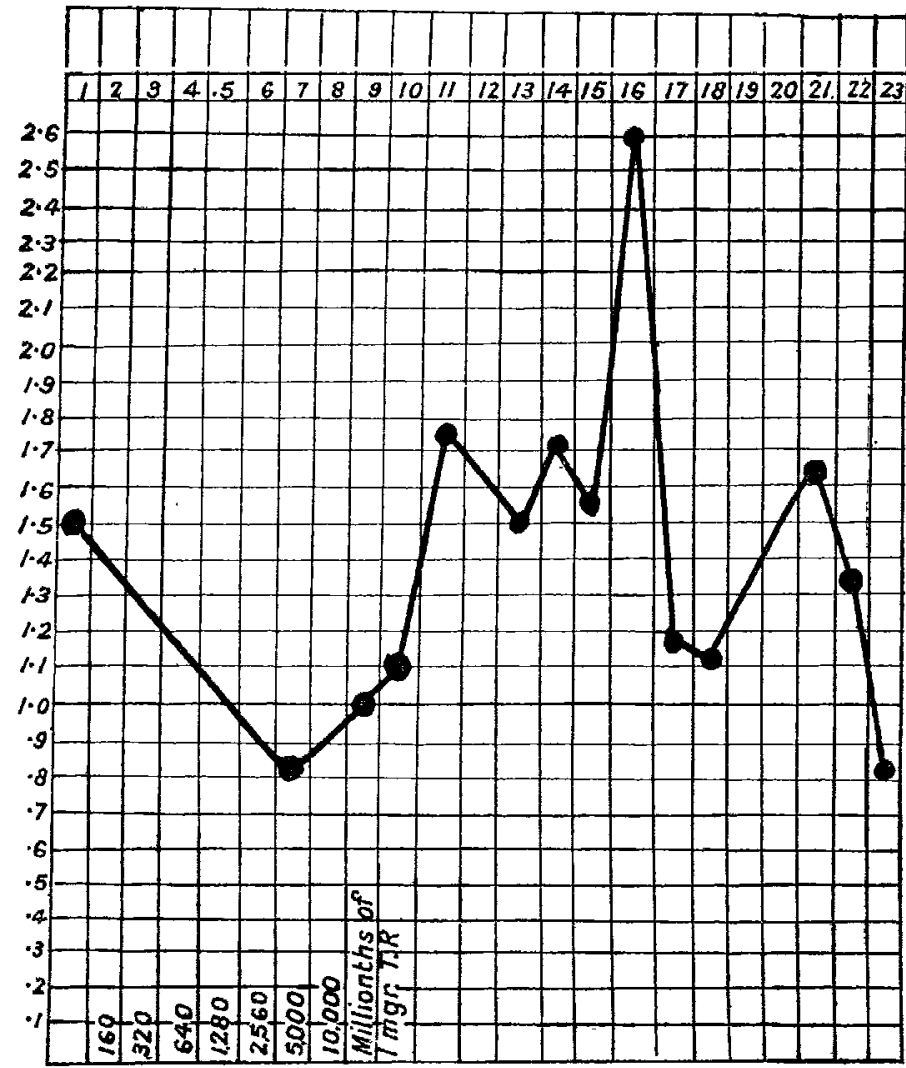

Effect of a series of rapidly increasing doses.

increasing in arithmetical progression it is necessary to use stimuli increasing in geometrical progression. This method appeared to be successful in certain cases but the results are inconclusive. As an instance of the result produced by these means the following observations may be taken. (See Chart 5.)

\begin{tabular}{|c|c|c|c|c|c|}
\hline & & & Index. & & $\begin{array}{l}\text { Dose } \\
\text { illionths } \\
\text { f } 1 \text { mgr. } \\
\text { T.R.). }\end{array}$ \\
\hline 1st & day & $\ldots$ & 1.5 & $\ldots$ & 0 \\
\hline 2 nd & , & $\ldots$ & - & $\ldots$ & 160 \\
\hline $3 r d$ & , & $\ldots$ & - & $\ldots$ & 320 \\
\hline 4 th & , & $\ldots$ & - & $\ldots$ & 640 \\
\hline 5 th & , & $\cdots$ & - & ... & 1,280 \\
\hline 6th & $"$ & $\ldots *$ & - & $\ldots$ & 2,560 \\
\hline 7th & ", & $\ldots$ & 0.82 & $\ldots$ & 5,000 \\
\hline 8 th & , & $\ldots$ & - & $\ldots$ & 10,000 \\
\hline 9th & , & $\ldots$ & $1 \cdot 0$ & $\ldots$ & 0 \\
\hline th & 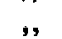 & $\ldots$ & $1 \cdot 1$ & $\ldots$ & 0 \\
\hline & 3 & $\ldots$ & $1 \cdot 75$ & $\ldots$ & 0 \\
\hline
\end{tabular}
Index. (millionths T.R.).

$\begin{array}{llllll}\text { 12th day } & \ldots & - & \ldots & 0 \\ \text { 13th } & , & \ldots & 1.5 & \ldots & 0 \\ 14 \text { th } & , & \ldots & 1.72 & \ldots & 0 \\ 15 \text { th } & , & \ldots & 1.55 & \ldots & 0 \\ 16 \text { th } & , & \ldots & 2.6 & \ldots & 0 \\ 17 \text { th } & , & \ldots & 1.18 & \ldots & 0 \\ 18 \text { th } & , & \ldots & 1.12 & \ldots & 0 \\ 19 \text { th } & , & \ldots & - & \ldots & 0 \\ 20 \text { th } & , & \ldots & 1.62 & \ldots & 0 \\ \text { 21st } & , & \ldots & 1.22 & \ldots & 0 \\ \text { 22nd } & , & \ldots & 0.86 & \ldots & 0\end{array}$

From this table it would appear that it is possible by rapidly increasing doses to raise the opsonic index for a considerable period. We are not, however, at present justified in stating this as a fact universally true.

We have had under observation 32 tuberculous patients during the last six months. We have estimated the opsonic index on 492 separate occasions. In the present communication we do not pretend to define the value of tuberculin in treatment, or of the opsonic index as a guide to that treatment. It has first to be discovered how the opsonic index can be artificially modified, and only later does the problem arise as to what the effect of that modification is on the patient's health. We here have only ventured to record a few of our observations in the hope that they may be of some slight assistance to other workers in the same field. 